\title{
Self-aggregated perfluoroalkylated hexa-peri-hexabenzocoronene fibers observed by cryo-SEM and fluorescence spectroscopy $\dagger$
}

\author{
Olivier F. Aebischer, ${ }^{a}$ Annina Aebischer, ${ }^{b}$ Patrick Tondo, ${ }^{a}$ Bassam Alameddine, ${ }^{c}$ Massoud Dadras, ${ }^{d}$ \\ Hans-Ulrich Güdel $^{b}$ and Titus A. Jenny*a
}

The self-assembled architectures in solution of a new $\mathrm{HBC}$ derivative bearing perfluoroalkylated side chains were investigated by optical excitation and emission spectroscopy and correlated to cryo-SEM, a new technique in organic chemistry.

The ability of molecules to self-assemble into highly ordered architectures has gained increasing importance in the past decade, as these nano-objects are applicable in the field of optical and electronic devices. ${ }^{1}$ Of particular interest are linear conducting structures, so called nanowires. Most of the nanowires reported so far consist of inorganic and metallic materials ${ }^{2}$ and only a few studies have presented organic based nanowires which have been employed as semiconductors. ${ }^{3}$ Hexa-peri-hexabenzocoronene (HBC), often called superbenzene, ${ }^{4}$ self-organizes into columnar architectures, by $\pi$-stacking, with an outstanding degree of order in the solid state. ${ }^{5}$ This unprecedented property provides HBC with the highest charge carrier mobility in the bulk recorded so far, ${ }^{6}$ presenting a promising candidate for electronic ${ }^{7}$ and optoelectronic ${ }^{8}$ devices. HBC derivatives bearing aliphatic side chains, which provide a better solubility in organic solvents and influence the association between the molecules, have been reported. ${ }^{9}$ Even though those aliphatic chains bestow on the HBC a liquid crystalline property, their crystallization ${ }^{10}$ and hence aggregation with the side chains of neighboring stacks hinders the formation of very long nanometer sized freestanding filaments.

Herein, we present our first results on a novel HBC derivative, HBC- $\left[\left(\mathrm{CH}_{2}\right)_{4}\left(\mathrm{CF}_{2}\right)_{6} \mathrm{~F}\right]_{6}(\mathbf{1})$, bearing six side chains each consisting of an alkylated and a perfluoroalkylated section. The alkylated section acts as a four-carbon spacer between the core structure and the six-carbon perfluorinated tail. Preliminary investigations on aliphatic spacers of variable length $n(n=2-6)$ indicate that the four-carbon aliphatic spacer chosen for this investigation presents an optimum for the following parameters: $i$ ) total isolation of the

${ }^{a}$ Department of Chemistry, University of Fribourg, chemin du Musée 9 , 1700 Fribourg, Switzerland. E-mail: titus.jenny@unifr.ch;

Fax: +41 26300 9739; Tel: +41263008778

${ }^{b}$ Department of Chemistry and Biochemistry, University of Bern, Feiestrasse 3, 3000 Bern 9, Switzerland.E-mail: guedel@iac.unibe.ch; Fax: +41 31631 4399; Tel: +41316314249

${ }^{c}$ Department of Chemistry, University of Balamand, Tripoli, Lebanon. E-mail: balameddine@hotmail.com; Fax:+9611663885;

Tel: $+41+9616930250$

${ }^{d}$ Service for Microscopy and Nanoscopy, IMT, University of Neuchâtel, 2007 Neuchâtel, Switzerland.E-mail: massoud.dadras@unine.ch; Fax: +4132720 5711; Tel: +41327205248

$\dagger$ Electronic supplementary information (ESI) available: Experimental procedures, MALDI-ICR and ${ }^{1} \mathrm{H}-\mathrm{NMR}$ spectra of HBC 1, cryo-SEM and SEM micrographs. See DOI: 10.1039/b609056g electron withdrawing effect of the perfluoro chain from the core structure; ii) allowing for maximum flexibility between the rigid core structure and the semi-rigid perfluoroalkyl tail; ${ }^{11}$ iii) short enough to prevent crystalline alkyl chain-alkyl chain interactions. The seemingly very minor change in the length of the perfluorinated part, six carbons instead of eight as in our previous work, ${ }^{12}$ had a tremendous impact on the solubility of the new compound in a range of solvents such as 1,2,4-trichlorobenzene (TCB), benzotrifluoride (BTF) and hexafluorobenzene (HFB), whereas the compound with $\left(\mathrm{CH}_{2}\right)_{4}\left(\mathrm{CF}_{2}\right)_{8} \mathrm{~F}$ side chains showed very low solubility in all solvents, severely hampering its purification. Nevertheless, the most important property of $\mathrm{HBC}$ $\left[\left(\mathrm{CH}_{2}\right)_{4}\left(\mathrm{CF}_{2}\right)_{8} \mathrm{~F}\right]_{6}$, i.e. its tendency to form very long monostranded molecular stacks, was fully retained in the new variant.

Scheme 1 illustrates the six step synthesis of $\mathbf{1}$ which is obtained as a bright yellow solid. ${ }^{13}$ Compound $\mathbf{1}$ was investigated by cryo scanning electron microscopy (cryo-SEM) and optical luminescence and excitation spectroscopy. Cryo-SEM, ${ }^{14}$ a new technique in organic chemistry, was chosen instead of regular SEM, since it allows the examination of supramolecular structures pre-existing in solution, which would otherwise aggregate to solids in the usual target preparation involving application of a solution containing the analyte to the target followed by evaporation of the solvent. In cryo-SEM the applied BTF solution is shock frozen in liquid nitrogen further cooled below $63 \mathrm{~K}$ and transferred in this state to the cryo transfer system (Gatan ALTO 2500) of the microscope. Subsequently the solvent is sublimed off the sample in the high vacuum of the instrument. ${ }^{15}$ Supramolecular aggregates pre-existing in solution are conserved by this technique, and subsequently fixed by $\mathrm{Pt}$ sputtering (15 nm coating) and investigated.

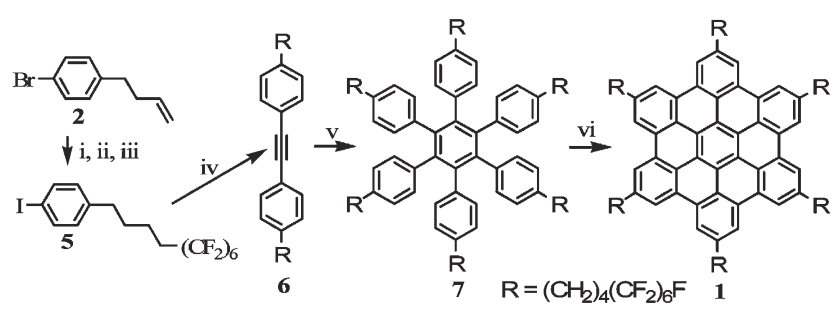

Scheme 1 Synthesis of HBC-[( $\left.\left(\mathrm{CH}_{2}\right)_{4}\left(\mathrm{CF}_{2}\right)_{6} \mathrm{~F}\right]_{6}$ 1: i) $\mathrm{C}_{6} \mathrm{~F}_{13} \mathrm{I}, \mathrm{AIBN}, 30 \%$ aq. $\mathrm{Na}_{2} \mathrm{~S}_{2} \mathrm{O}_{5}, 80{ }^{\circ} \mathrm{C}, 98 \%$; ii) $\mathrm{LiAlH}_{4}$, THF, r.t., $77 \%$; iii) Ni, KI, I 2 , DMF, $150{ }^{\circ} \mathrm{C}, 83 \%$; iv) $\mathrm{Pd}\left(\mathrm{PPh}_{3}\right)_{4}$, CuI, DBU, TMSA, $\mathrm{H}_{2} \mathrm{O}$, THF, $80{ }^{\circ} \mathrm{C}, 44 \%$; v) $\mathrm{Co}_{2}(\mathrm{CO})_{8}$, dioxane, $110{ }^{\circ} \mathrm{C}, 90 \%$; vi) $\mathrm{FeCl}_{3}, \mathrm{CH}_{3} \mathrm{NO}_{2}, \mathrm{CH}_{2} \mathrm{Cl}_{2}, 45^{\circ} \mathrm{C}$, $70 \%$. 
Three BTF solutions of 1 at different concentrations $\left(10^{-4} \mathrm{M}\right.$, $10^{-5} \mathrm{M}$ and $10^{-6} \mathrm{M}$ ) were investigated by cryo-SEM. The investigation of a highly concentrated solution $\left(10^{-4} \mathrm{M}\right)$ revealed the presence of large bundles of laterally aggregated HBC columns with an average length of about $20 \mu \mathrm{m}$ and a cross section of typically $500 \times 200 \mathrm{~nm}$, representing an architecture consisting of approx. 10,000 laterally aggregated columns (see Fig. 1a). The remarkable bending observed for the long axis of these structures implies considerable non-crystallinity in the lateral aggregation of these supramolecular stacks. At an intermediate concentration $\left(10^{-5} \mathrm{M}\right)$, thinner bundles of HBC columns were observed, having a cross section of about $250 \times 50 \mathrm{~nm}$, extending still over $20 \mu \mathrm{m}$ in length (approx. 400 aggregated columns, see Fig. 1b and 1c). At low concentration $\left(10^{-6} \mathrm{M}\right)$, only isolated HBC fibres were found with an apparent diameter of $25 \mathrm{~nm}$ and $3 \mu \mathrm{m}$ typical length, indicating a freestanding monocolumnar linear architecture (Fig. 1d). As the observed diameter of $25 \mathrm{~nm}$ is due essentially to the applied platinum coating $(15 \mathrm{~nm})$, we assume that this diameter, uniform for all filaments, nevertheless proves the existence of laterally non aggregated structures.

BTF solutions of 1 ranging from $10^{-4} \mathrm{M}$ to $10^{-10} \mathrm{M}$ were investigated by optical spectroscopy. At low concentrations $\left(10^{-6} \mathrm{M}\right.$ to $\left.10^{-10} \mathrm{M}\right)$ excitation, fluorescence and absorption spectra reveal typical bands of $\mathrm{HBC}$ derivatives ${ }^{16}$ (Fig. 2). By increasing the concentration to $10^{-5} \mathrm{M}$ or $10^{-4} \mathrm{M}$, intense and broad red-shifted luminescence bands appear which can be attributed to $\mathrm{HBC}$ columns and aggregates by comparison to the data collected by cryo-SEM. Moreover, the solid state luminescence spectrum of the precipitate collected from the $10^{-4} \mathrm{M}$ solution reveals similar red shifted bands. Nevertheless, the observed differences of the solid state emission in spectrum 2a) as compared to the emission spectrum in solution at $10^{-4} \mathrm{M}$ suggest the presence of at least two different types of aggregates in solution. Cryo-SEM observations support this assumption, showing that large laterally aggregated fibres are observed at medium to high concentration in addition to monostranded stacks (Fig. 1a).

In conclusion, cladding $\mathrm{HBC}$ with "Teflon" like side chains makes it possible to control the self-assembly into highly ordered architectures. Cryo-SEM correlated to optical excitation and

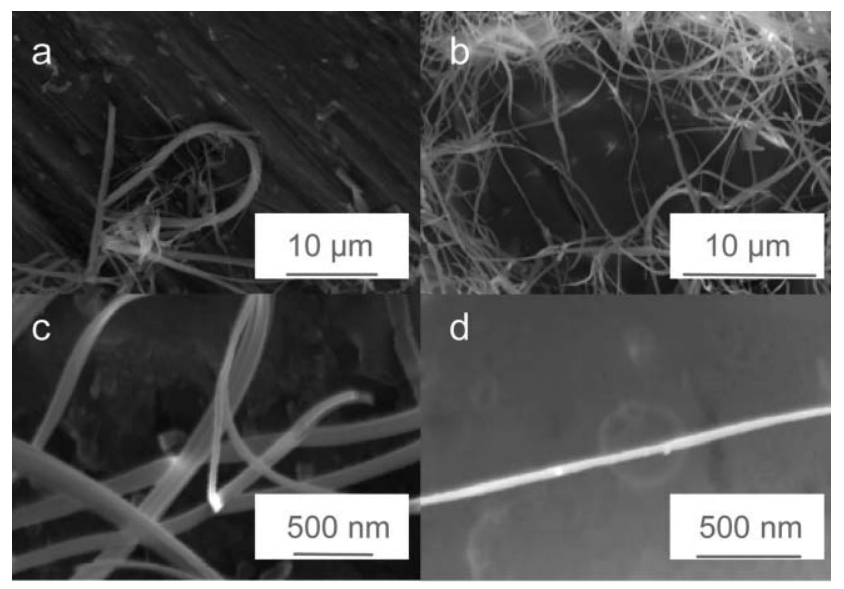

Fig. 1 Micrographs obtained by cryo-SEM of $\mathrm{HBC}-\left[\left(\mathrm{CH}_{2}\right)_{4}\left(\mathrm{CF}_{2}\right)_{6} \mathrm{~F}\right]_{6}$ nanostructures in BTF at different concentrations: (a) $10^{-4} \mathrm{M}$; (b), (c) $10^{-5} \mathrm{M}$; (d) $10^{-6} \mathrm{M}$.

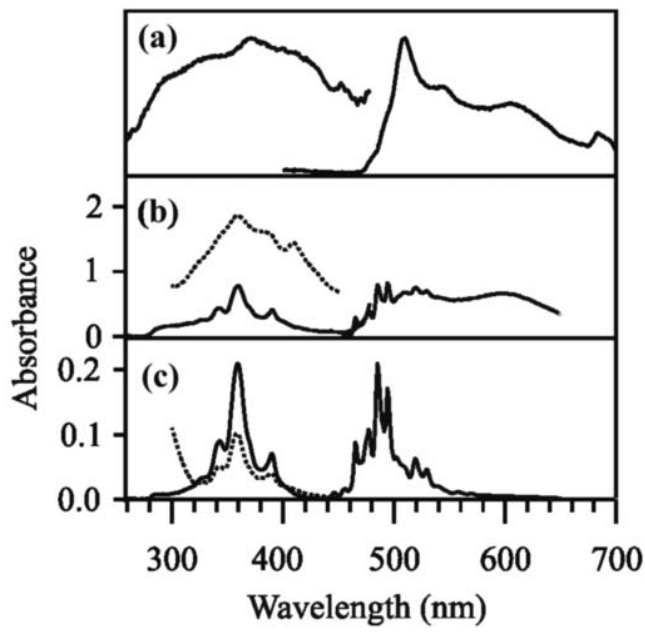

Fig. 2 Optical spectroscopy: (a) Excitation spectrum $\left(\lambda_{\mathrm{det}}=509 \mathrm{~nm}\right)$ and fluorescence spectrum $\left(\lambda_{\mathrm{ex}}=360 \mathrm{~nm}\right)$ of the solid precipitated from a $10^{-3} \mathrm{M}$ solution of $\mathrm{HBC}-\left[\left(\mathrm{CH}_{2}\right)_{4}\left(\mathrm{CF}_{2}\right)_{6} \mathrm{~F}\right]_{6}$ (1) in BTF. (b) Excitation spectrum $\left(\lambda_{\mathrm{det}}=485 \mathrm{~nm}\right)$, fluorescence spectrum $\left(\lambda_{\mathrm{ex}}=360 \mathrm{~nm}\right)$, and absorption spectrum (dotted line) of a solution of $10^{-4}$ M 1 in BTF. (c) Same as in (b) but for a solution of $10^{-6}$ M 1 in BTF. Note that the intensities of the excitation and fluorescence spectra of (b) can be compared with those of (c). Note also the different absorbance scales of (b) and (c). The luminescence spectra are arbitrarily scaled.

emission spectroscopy provides a powerful tool for monitoring the formation of such structures.

\section{Notes and references}

1 M. Law, J. Goldberger and P. Yang, Annu. Rev. Mater. Res., 2004, 34, $83-122$.

2 S. Sharma, H. Li, H. Chandrasekaran, R. C. Mani and M. K. Sunkara, Encyclopedia of Nanoscience and Nanotechnology, H. S. Halwa, Ed., American Scientific Publishers, Los Angeles, 2004, vol. 10, pp. 327-346.

3 (a) H. J. Lee, Z. X. Jin, A. N. Aleshin, J. Y. Lee, M. J. Goh, K. Akagi, Y. S. Kim, D. W. Kim and Y. W. Park, J. Am. Chem. Soc., 2004, 126, 16722-16723; (b) P. Leclère, M. Surin, P. Jonkheijm, O. Henze, A. P. H. J. Schenning, F. Biscarini, A. C. Grimsdale, W. J. Feast, E. W. Meijer, K. Müllen, J. L. Brédas and R. Lazzaroni, Eur. Polym. J., 2004, 40, 885-892.

4 (a) E. Clar, Aromatische Kohlenwasserstoffe-Polycyclische Systeme, Springer, Berlin, 1952; (b) E. Clar, The Aromatic Sextet, Wiley, London, 1972.

5 (a) P. Ruffieux, O. Gröning, M. Bielman, C. Simpson, K. Müllen, L. Schlapbach and P. Gröning, Phys. Rev. B, 2002, 66, 073409/ 073401-073409/073404; (b) O. Bunk, M. M. Nielsen, T. I. Solling, A. M. van de Craats and N. Stutzmann, J. Am. Chem. Soc., 2003, 125, 2252-2258.

6 A. M. van de Craats and J. M. Warmann, Adv. Mater., 2001, 13, $130-133$.

7 A. M. van de Craats, N. Stutzmann, O. Bunk, M. M. Nielsen, M. Watson, K. Müllen, H. D. Chanzy, H. Sirringhaus and R. H. Friend, Adv. Mater., 2003, 15, 495-499.

8 (a) C.-Y. Liu, A. Fechtenkötter, M. D. Watson, K. Müllen and A. Bard, J. Chem. Mater., 2003, 15, 124-130; (b) L. Schmidt-Mende, A. Fechtenkötter, K. Müllen, E. Moons, R. H. Friend and J. D. MacKenzie, Science, 2001, 293, 1119-1122; (c) M. O'Neill and S. M. Kelly, Adv. Mater., 2003, 15, 1135-1146.

9 J. Wu, A. Fechtenkötter, J. Gauss, M. D. Watson, M. Kastler, C. Fechtenkötter, M. Wagner and K. Müllen, J. Am. Chem. Soc., 2004, 126, 11311-11321.

10 M. Kastler, W. Pisula, D. Wasserfallen, T. Pakula and K. Müllen, J. Am. Chem. Soc., 2005, 127, 4286-4296. 
11 D. F. Eaton and B. E. Smart, J. Am. Chem. Soc., 1990, 112, 2821-2823.

12 B. Alameddine, O. F. Aebischer, W. Amrein, B. Donnio, R. Deschenaux, D. Guillon, C. Savary, D. Scanu, O. Scheidegger and T. A. Jenny, Chem. Mater., 2005, 4798-4807.

13 O. F. Aebischer, P. Tondo, B. Alameddine and T. A. Jenny, Synthesis, 2006 (DOI: 10.1055/s-2006-942550).

14 P. Echlin, Low-Temperature Microscopy and Analysis, Plenum Press, New York, 1992.
15 Sublimation at $-95{ }^{\circ} \mathrm{C}$ for 20 minutes at $2 \cdot 10^{-5}$ mbar, investigation afterwards at $-150{ }^{\circ} \mathrm{C}, 10^{-5}$ mbar.

16 (a) J. C. Fetzer and M. Zander, Z. Naturforsch., A: Phys. Sci., 1990, 45, 727-729; (b) Z. Wang, Z. Tomovic, M. Kastler, R. Pretsch, F. Negri, V. Enkelmann and K. Müllen, J. Am. Chem. Soc., 2005, 126, 7794-7795; (c) M. A. Biasutti, J. Rommens, A. Vaes, S. De Feyter, F. D. De Schryver, P. Hertwig and K. Müllen, Bull. Soc. Chim. Belg., 1997, 106, 659-664. 